Email: jkesislam@unisma.ac.id

Home Page : http://riset.unisma.ac.id/index.php/jki

\title{
ASTROCYTOMA MIMICKING STROKE PADA PASIEN PRIA DEWASA MUDA
}

\author{
Rima Zakiyah ${ }^{1}$, Shinta Kusumawati ${ }^{2}$ \\ ${ }^{1}$ Departemen Radiologi Fakultas Kedokteran Universitas Islam Malang, ${ }^{2}$ Departemen Neurologi \\ Fakultas Kedokteran Universitas Islam Malang
}

\begin{abstract}
Abstrak
Astrocytoma adalah tumor otak terbanyak, lebih dari separuh keganasan pada sistem saraf pusat. Pasien dengan astrocytoma hemisferik sering datang dengan klinis kejang dan berbagai gejala sehingga diagnosa menjadi sukar. Astrocytoma menginfiltrasi jaringan otak, namun efeknya pada fungsi otak hanya sedikit sekali pada awal penyakit. Dilaporkan, laki laki usia 19 tahun, oleh bagian neurologi awalnya pasien diduga mengalami Cerebro Vascular Accident (CVA) trombosis, karena terjadi disartria akut (saat pasien istirahat), didahului kesulitan bicara dan riwayat kelemahan badan sebelah kiri, serta riwayat kejang fokal selama kurang dari 1 menit setahun sebelumnya. Pemeriksaan Neurologis didapatkan parese N. VII sinistra UMN, penurunan motoris ekstremitas sebelah kiri (4), peningkatan refleks fisiologis sinistra, serta peningkatan tonus. Hasil pemeriksaan Radiologi (CT scan kepala) adalah tumor supratentorial pada lobus frontoparietal dextra suspect high grade astrocytoma yang menyebabkan edema perifokal dan herniasi subfalsin ke sinistra dengan Leptomeningeal carcinomatosis. Ketidaksesuaian diagnosa awal dengan hasil CT, karena tumor bisa memberikan manifestasi klinis yang sangat luas dan kadang menyerupai suatu CVA karena efek penekanan massa terhadap vaskular atau gangguan vaskular akibat infiltrasi massa/ sel metastase.
\end{abstract}

Kata kunci: Astrocytoma, Cerebrovascular Accident, CT scan

\section{PENDAHULUAN}

Astrocytoma adalah tumor otak terbanyak, lebih dari separuh keganasan pada sistem saraf pusat. Pasien dengan astrocytoma hemisferik datang dengan klinis kejang dan tidak jarang dengan berbagai gejala sehingga diagnosa menjadi sukar. Kasus terbanyak pada dekade pertama kehidupan. Reseksi dengan pembedahan cukup unutk astrocytoma low grade, sayangnya prognosa jeeak untuk astrocytoma high grade.

Astrocytoma menginfiltrasi otak dan sering berkaitan dengan kista pada berbagai ukuran. Walaupun menginfiltrasi jaringan otak, efeknya pada fungsi otak hanya sedikit sekali pada permulaan penyakit. Pada umumnya astrocytoma tidak ganas, walaupun dapat mengalami perubahan keganasan menjadi glioblastoma. Tumor yang jinak umumnya tumbuh lambat. Oleh karena itu penderita sering tidak datang berobat walaupun tumor sudah berjalan bertahun- tahun, sampai timbul gejala misalnya serangan epilepsi atau nyeri kepala.

Pemeriksaan CT mempunyai sensitifitas tinggi $(95 \%)$ untuk mendeteksi astrocytoma dan MRI merupakan modalitas yang terpilih untuk astrocytoma pada batang otak. MRI idealnya dilakukan pada pasien dengan kecurigaan klinis astrocytoma dan harus dibedakan dengan meduloblastoma atau ependymoma.

\section{LANDASAN TEORI}

\section{Astrocytoma}

Astrocytoma adalah tumor yang berasal dari sel astrocyt (salah satu jenis sel glia). Sinonimnya adalah glioma. Karakteristik tumor fibrilar, protoplasmic atau gemistocytic astrocyt yang tumbuh pelan tetapi invasif. Tergantung pada anaplasinya astrocyt dapat dibagi menjadi 4 gade:

- grade 1 : pilocytic astrocytoma

- grade 2 : difus astrocytoma (jaringan isomorfik dengan sedikit sel, tidak adan mitosis, jaringan vascular normal)

- grade 3 : anaplastic astrocytoma (densitas sel lebih besar, polimorfik sel dan nukleus, fokus nekrotik, dinding vascular dapat ditembus oleh kontras)

- grade 4 : glioblastoma multiforme (mitosis tinggi, jaringan polimorfik dengan fokus nekrotik luas dan vascular) 
Menurut topografinya astrocytoma dapat tumbuh pada semua hemisfer cerebri dengan lokasi terbanyak adalah lobus temporal dan frontal. Pons adalah lokasi tersering pada anak-anak kurang dari 10 tahun.

Pilocytic astrocytoma lokasi pada nervus opticus, hipotalamus, thalamus, ganglia basalis, hemisfer cerebri, cerebellum dan batang otak. Tumor menunjukkan proliferasi dan aktifitas mitotis ringan, jarang metastasis atau mengalami perubahan menjadi maligna. Umumnya tidak mengadakan infiltrasi dan dapat mengalami regresi spontan. Temuan pada analisa sitogenetik normal, atau kelainan pada kromosom 7 dan 8 .

Pilomyxoid astrocytoma merupakan variasi astrocytoma low grade pada pediatrik, awalnya diklasifikasikan dalam pilocytic astrocytoma tetapi ternyata mempunyai gambaran histologis yang berbeda dan lebih agresif, mempunyai kecenderungan untuk mengadakan penyebaran dan prognosa yang lebih buruk dibandingkan pilocytic astrocytoma.

Astrocytoma difus berkembang di cerebrum terutama pada lobus frontal dan temporal. Kadang terdapat pada batang otak atau corda spinalis dan jarang terdapat pada cerebellum. Merupakan tumor dengan infiltratif dan moderate celuler, membesar, tetapi tidak merusak, terjadi mutasi ada gen TP53, umumnya terjadi pada dewasa.

Astrocytoma anaplastik berkembang pada lokasi yang sama dengan astrocytoma difus dengan kecenderungan lebih pada hemisfer cerebri. Tumor menunjukkan nukleus atipical, celularitas tinggi, aktifitas mitotik tinggi dan kecenderungan unutk infiltrasi ke jaringan sekitar.

Glioblastoma adalah tumor terbanyak pada otak, menunjukkan karakteristik anaplasi dan malignancy tinggi. Area nekrosis besar, kista dan perdarahan pada bagian yang solid. Terjadi proliferasi endotel dan vascular dan dikeliligi edema luas. Lokasi terbanyak adalah white matter dan basal ganglia, invasi corpus calosum dan meluas pada 2 hemisfer (butterfly glioblastoma), dapat juga multipel.

\section{Leptomeningeal Carcinomatosis}

Leptomeningeal carcinomatosis adalah penyebaran difus metastase tumor pada leptomeningen, terjadi pada carcinoma mammae, paru, melanoma dan neuroectoderma pada anak.

\section{Insiden Astrocytoma}

Insiden terbanyak pada dekade pertama kehidupan dengan puncak usia 5-9 tahun. Merupakan tumor terbanyak pada anakanak. Rasio laki-laki terhadap perempuan 1:1. Pada astrocytoma low grade angka harapan hidup 5 tahun adalah 95-100\% dengan reseksi komplet. Pada astrocytoma high grade angka harapan hidup 5 tahun adalah $15-30 \%$ untuk supratentorial dan kurang dari $10 \%$ untuk infratentorial. Glioblastoma terjadi pada pria 2 kali lebih banyak dibanding wanita dan usia puncak dekade 5 sampai 7 dan jarang pada anak.

\section{Leptomeningeal Carcinomatosis}

Di Inggris ditemukan pada 2-25\% pasien keganasan dengan 204\% tumor primer tidak diketahui. Terjadi pada Ca mammae 5-34\%, small cell Ca paru 9-26\% dan melanoma 17$25 \%$.

\section{Manifestasi Klinis Astrocytoma}

Tumor otak menyebabkan gangguan neurologi progresif. Hal ini menekankan pentingnya ananmesa. Gangguan neurologi pada tumor otak biasanya dianggap disebabkan oleh 2 faktor: gangguan fokal disebabkan oleh tumor dan kenaikan tekanan intracranial. Gangguan fokal terjadi apabila terdapat penekanan pada jaringan otak, infiltrasi atau invasi langsung pada parenkim otak dengan kerusakan jaringan neuron. Perubahan suplai darah akibat tekanan yang ditimbulkan tumor, gangguan suplai darah arteri pada umumnya bermanifestasi sebagai kehilangan fungsi secara akut dan mungkin dapat dikacaukan dengan gangguan cerebrovascular primer. Serangan kejang sebagai manifestasi perubahan kepekaan neuron dihubungkan dengan kompresi, invasi dan perubahan suplai darah ke jaringan otak.

Dari anamnesa didapatkan keluhan biasanya dimulai setidaknya 3 bulan. Gejala awal tidak spesifik, tidak terlokalisasi dan berhubungan dengan peningkatan tekanan intracranial seperti nyeri kepala saat pagi hari, muntah dan letargi. Kejang terjadi pada $25 \%$ pasien dengan astrocytoma supratentorial. Gejala yang berkaitan dengan lokasi tumor yaitu: 
- defisit motoris terjadi $40 \%$ pada pasien dengan tumor hemisferik dan diencephic

- pasien dengan tumor diencephalic manifestasi sebagai sindrom diencephalic seperti emesis, eforia

- pasien dengan astrocytoma cerebellum manifestasi sebagai kelemahan, dismetria, tremor dan ataksia

- astrocytoma pada batang otak manifestasi sebagai hemiparesis kontralateral

- astrocytoma pada jalur visual manifestasi sebagai strabismus, proptosis, nistagmus dan gangguan perkembangan mental

- astrocytoma pada corda spinalis manifestasi sebagai nyeri, kelemahan, gangguan gait, parestesis dan disfungsi sphingter

Pada pemeriksaan fisik didapatkan tanda peningkatan tekanan intracranial seperti:

- pemeriksaan funduskopi menunjukkan papiledema dan nervus opticus terlihat pucat

- kelumpuhan nervus cranial VI dan ketidakmampuan abduksi 1 atau 2 mata

Tanda lain menunjukkan:

- kelemahan, monoplegi atau hemiplegi

- multipel deficit nervus cranialis

- penurunan ketajaman penglihatan pada optic glioma

- astrocytoma spinal menunjukkan kelemahan berbagai derajat dari monoparesis sampai quadriparesis

\section{Leptomeningeal Carcinomatosis}

Keluhan pasien timbul karena efek emboli tumor atau jepitan saraf, invasi ke corda spinalis atau otak dan obstruksi cairan cerebrospinalis. Tumor primer menyebar ke leptomeningen lewat berbagai cara:

- ekstensi langsung pada tumor primer periventrikel atau pada parenkim otak dimana lokasi tumor tersebut dekat dengan aliran CSF, terjadi pada meduloblastoma, glioblastoma multiforme, ependimoma

- Metastase lewat arteri dengan ruptur piamater

- meluas secara perineural lewat nervus cranialis

- hematogen lewat vena yang berada di ruang sub arachnoid

\section{Pemeriksaan Radiologis Astrocytoma}

CT scan kepala tanpa dan dengan kontras menunjukkan :

- kebanyakan astrocytoma supratentorial menunjukkan lesi hipodens dengan derajat penyangatan kontras berbedabeda

- $\quad$ kalsifikasi bisa ada/ tidak

- pilocytic astrocytoma (grade 1) tampak sebagai lesi bulat, hipodens atau isodens dengan kista dan kadang kalsifikasi. Perifokal edema jarang didapat. Dengan penambahan kontras struktur solid tampak menyangat sedangkan struktur kistik tidak menyangat. Pada cerebellum letaknya eksentrik, menekan ventrikel IV dan menyebakan hidrocephalus obstruktif.

- astrocytoma grade 2 tampak sebagai area dengan penurunan densitas. Perifokal edema tidak selalu muncul. Tidak selalu ada efek massa. Tumor tidak menyangat setelah pemberian kontras dan kadang sukar dibedakan dengan infark. Dengan melihat topografi dan batas yang semakin jelas pada CT follow up, dapat dicurigai suatu astrocytoma

- astrocytoma grade 3 tampak pada CT dengan densitas yang lebih bervariasi, dapat densitas turun/ campuran / meningkat. Kebanyakan menyangat setelah pemberian kontras dan dikelilingi oleh edema perifokal.

- glioblastoma tampak pada CT sebagai lesi dengan densitas bervariasi dengan area nekrotik, kista dan perdarahan, dijkelilingi edema luas, dengan penambahan kontras tampak penyangatan (highly vascular)

- astrocytoma batang otak tidak menyangat setelah pemberian kontras, tanpa kalsifikasi dan tampak hipodens atau isodens

MRI tanpa dan dengan kontras gadolinium:

- MRI berguna untuk memperjelas anatomi dan ekstensi tumor

- astrocytoma pilocytic tampak hipointens pada T1 dan hiperintens pada $\mathrm{T} 2$, dengan atau tanpa struktur kistik

- astrocytoma anaplastik tampak hipointens heterogen pada T1 dan hiperintens heterogen pada $\mathrm{T} 2$

- glioblastoma tampak heterogen pada T1 dan $\mathrm{T} 2$ dengan penyangatan heterogen yang menunjukkan nekrosis 
Scintigrafi mungkin menunjukkan defek perfusi pada tumor. Tumor grade 2 tidak melakukan up take terhadap radiofarmaka. Angiografi sering negatif tetapi dapat pula menunjukkan perpindahan posisi vascular. Tumor grade 2 avascular dan grade 3 sangat hipervascular.

\section{Leptomeningeal carcinomatosis}

Pada pemeriksaan CT bisa didapatkan komplikasi akibat penyebaran sel tumor seperti hidrocephalus non communicating, penyangatan meningen, atrofi cerebri. Penyangatan tampak sebagai nodul multipel, penyangatan meningen/ ependim/ dural. Pada corda spinalis tampak penebalan radix dan berkelok, tumor menempel pada permukaaan corda spinalis atau berada di dalam canalis spinalis menyebabkan blokade aliran cerebrospinal.

\section{Terapi Astrocytoma}

Terapi astrocytoma tergantung pada lokasi dan derajat tumor, pasien dengan hidrocephalus obstruktif memerlukan penempatan ventriculoperitoneal shunt.

\section{Kemoterapi}

- mempunyai peran dan keberhasilan yang terbatas pada terapi astrocytoma

- untuk low grade astrocytoma yang inoperable karena lokasi, diberikan carboplatin dan vincristine

- perannya sangat terbatas pada pasien dengan high grade astrocytoma dengan pemberian temozolomide dan agen alkilasi

\section{Low grade astrocytoma}

- untuk low grade astrocytoma reseksi merupakan modalitas primer, jika mungkin dilakukan reseksi komplit untuk mencegah rekurensi

- $\quad$ pada kasus inoperable seperti lokasi di batang otak atau diencephalic, pertumbuhan ulang maka dilakukan radioterapi dengan batas $2 \mathrm{~cm}$ dari tepi tumor

\section{High grade astrocytoma}

- setelah reseksi dilakukan radioterapi lokal dengan dosis 50-60 Gy dengan tepi 2-4 $\mathrm{cm}$ dari tepi tumor

Astrocytoma pada batang otak

- merupakan kasus inoperable
- dilakukan radioterapi lokal dengan dosis 54 Gy

Astrocytoma corda spinalis

- reseksi komplit sangat sukar dilakukan

- dilakukan radioterapi dengan dosis 50 Gy

\section{Komplikasi Astrocytoma}

Komplikasi yang dapat timbul:

- $\quad$ hidrocephalus obstruktif

- defisit neurologis

- $\quad$ komplikasi akibat radiasi:

$$
\begin{array}{ll}
\bigcirc & \text { disfungsi endokrin } \\
\bigcirc & \text { mikroangipati } \\
\bigcirc & \text { anorexia }
\end{array}
$$

- $\quad$ komplikasi akibat kemoterapi:

$$
\begin{array}{ll}
\circ & \text { mielosupresi } \\
\bigcirc & \text { gangguan fertilitas }
\end{array}
$$

\section{Prognosa}

- angka harapan hidup mendekati $100 \%$ untuk astrocytoma yang dapat direseksi komplit

- tumor supratentorial mungkin menyebabkan gangguan motorik dan kejang yang sifatnya menetap

High Grade Astrocytoma:

- angka harapan hidu $<30 \%$ dengan disfungsi endokrin, kognisi atau motorik

Astrocytoma batang otak:

- bila dapat dilakukan reseksi komplit angka harapan hidup melebihi $90 \%$

- pada area tertentu pembedahan dapat berakibat paralise nervus cranialis multipel, mutisme dan gangguan respirasi

Astrocytoma corda spinalis:

- pada low grade astrocytoma dengan reseksi dan radioterapi angka harapan hidup $67 \%$

- pada high grade astrocytoma jarang bertahan hidup

\section{LAPORAN KASUS}

$\begin{array}{ll}\text { Identitas } & : \text { SH } \\ \text { Nama } & : 19 \text { tahun } \\ \text { Umur } & : \text { Laki-laki } \\ \text { Jenis Kelamin } & : \text { Pandaan } \\ \text { Alamat } & : \text { Tidak bekerja } \\ \text { Pekerjaan } & : 11 \text { Desember } \\ \text { MRS } & \\ 2016 & \\ \text { No Reg/ Billing } & : 10675211 / 732892\end{array}$


Anamnesa (autoanamnesa)

Keluhan utama : bicara pelo

Anamnesa :

Pasien mendadak bicara pelo 4 hari sebelum MRS, saat pasien sedang menonton TV, awalnya tidak bisa bicara tetapi kemudian bicara pelo. Kelemahan badan sebelah kiri sejak 2 bulan. Nyeri kepala (-), muntah (-), BAB dan BAK normal. Satu tahun sebelumnya kejang pada badan sebelah kiri, kurang dari 1 menit dan pasien tetap sadar. Kejang terjadi pada tangan, kaki dan wajah sebelah kiri. Kemudian pasien kontrol ke poli neurologi RSSA, tidak mengalami kejang lagi tetapi badan sebelah kiri terasa lemah (terapi Carbamazepin 1x1.5 dan forneuro 1x1). Nyeri kepala kanan, hilang timbul sejak 1 tahun yang lalu, kurang lebih 1 menit, dipakai istirahat sembuh. Hipertensi (-), Diabetes Melitus (-). Rokok (-), minuman keras pernah mencoba waktu SMP, sekarang tidak pernah lagi.

\subsection{Pemeriksaan Fisik dan Mental}

Status Interna Singkat

$\begin{array}{ll}\text { Tensi } & : 120 / 90 \mathrm{mmHg} \\ \text { Nadi } & : 112 \mathrm{x} / \mathrm{menit} \\ \text { RR } & : 20 \mathrm{x} / \mathrm{menit} \\ \text { Tax } & : 36.5^{\circ} \mathrm{C} \\ \text { Kepala/ Leher } & : \text { anemi (-), icteric (-) }\end{array}$

Thorax, abdomen, extremitas : normal

\section{Status Psikiatri Singkat}

normal

\section{Status Neurologis (waktu MRS)}

Kesadaran GCS: 456 (jumlah 15)

Fungsi luhur kortex:

$$
\begin{aligned}
& \text { pembicaraan dan berbahasa } \\
& \text { : normal } \\
& \text { kelainan fungsi luhur lain : normal } \\
& \text { pemahaman } \\
& \text { : normal } \\
& \text { penamaan } \\
& \text { : normal } \\
& \text { pengulangan } \\
& \text { : normal }
\end{aligned}
$$

Nervus cranialis

Tanda meningeal : -

$$
\begin{aligned}
& \text { : pupil bulat } \\
& \text { isokor, } \varnothing 7 \mathrm{~mm} / 7 \\
& \mathrm{~mm}, \text { reflek } \\
& \text { cahaya }+/+, \\
& \text { reflek cornea } \\
& +/+
\end{aligned}
$$

Saraf Otak N I-XII

$\begin{array}{ll}\text { N I } & : \text { normal } \\ \text { N II } & : \text { normal } \\ \text { N III } & : \text { normal } \\ \text { N IV } & : \text { normal }\end{array}$

$\begin{array}{cl}\text { N V } & : \text { normal } \\ \text { N VI } & : \text { normal } \\ \text { N VII } & : \text { parese N VII } \\ \text { sinistra UMN } & \\ \text { N VIII } & \text { normal } \\ \text { N IX } & : \text { normal } \\ \text { N X } & : \text { normal } \\ \text { N XI } & : \text { normal } \\ \text { N XII } & : \text { normal }\end{array}$

Sistem Motorik :

Tonus

$\begin{array}{lr}\mathrm{N} & \uparrow \\ \mathrm{N} & \uparrow\end{array}$

Kekuatan
\begin{tabular}{|l|l|l|l|l|l|}
\hline otot & $\begin{array}{c}\text { ka } \\
\text { na } \\
\mathbf{n}\end{array}$ & $\begin{array}{c}\text { ki } \\
\mathbf{r i}\end{array}$ & otot & $\begin{array}{c}\text { ka } \\
\mathbf{n a} \\
\mathbf{n}\end{array}$ & $\begin{array}{c}\text { ki } \\
\mathbf{r i}\end{array}$ \\
\hline $\begin{array}{l}\text { Bah } \\
\text { u }\end{array}$ & 5 & 4 & $\begin{array}{l}\text { Pan } \\
\text { ggul }\end{array}$ & 5 & 4 \\
\hline Situ & 5 & 4 & $\begin{array}{l}\text { Lutu } \\
\text { t }\end{array}$ & 5 & 4 \\
\hline $\begin{array}{l}\text { Tan } \\
\text { gan }\end{array}$ & 5 & 4 & $\begin{array}{l}\text { Kak } \\
\text { i }\end{array}$ & 5 & 4 \\
\hline jari & 5 & 4 & jari & 5 & 4 \\
\hline
\end{tabular}

Tes Cerebellum : sulit dievaluasi

Gerakan tidak sadar : :

Refleks Fisiologis

$$
\begin{array}{ll}
+2 & +3 \\
+2 & +3 \\
+2 & +3 \\
+2 & +4
\end{array}
$$

Refleks Patologis :

$$
\begin{array}{ll}
\text { Babinski: -/+ } & \\
\text { Chaddok } & :-/+ \\
\text { Openheim } & :-/-
\end{array}
$$

Gordon :-/-

Refleks Regresi : -

Pemeriksaan bayi dan anak

Sistem sensorik :

$\begin{array}{ll}\mathrm{N} & \mathrm{N} \\ \mathrm{N} & \mathrm{N}\end{array}$

Sistem saraf otonom : normal

Sistem kepala dan Columna Vertebralis : normal

Diagnosa Kerja (sementara)

Diagnosa klinis :

$$
\begin{array}{ll}
\text { - } & \text { akut disartria } \\
\text { - } & \text { reflek fisiologis } \\
& \text { sinistra } \uparrow \\
\text { - } & \text { hemiparese } \\
& \text { sinistra } \\
\text { - } & \text { parese N VII } \\
& \text { sinistra UMN } \\
\text { - } & \text { tonus } \\
\mathrm{N} & \uparrow
\end{array}
$$




\begin{tabular}{ll}
\multicolumn{1}{c}{$\mathrm{N}$} & $\uparrow$ \\
$\begin{array}{l}\text { Diagnosa topis } \\
\text { media) }\end{array}$ & cortex (arteri cerebri \\
$\begin{array}{l}\text { Diagnosa etiologis } \\
\text { trombosis }\end{array}$ & : Susp CVA \\
$\begin{array}{l}\text { Diagnosa banding } \\
\begin{array}{l}\text { Diagnosa sekunder } \\
\text { (minuman keras) }\end{array}\end{array}$ & $:$ CVA ICH \\
\end{tabular}

\section{$\underline{\text { Rencana Pemeriksaan }}$}

- CT scan

- darah lengkap

- fungsi ginjal

- fungsi hati

- foto thorax

- gula darah

- elektrolit

- VDRL

- TPHA

- TB Dot

\section{Rencana Pengobatan dan Tindakan \\ - pasang venflon \\ - $\operatorname{diet}$ TKTP \\ - injeksi brain act $2 \times 1$ \\ - injeksi calmeco $1 \mathrm{x} 1$ \\ - $\quad$ po CPZ 1x100 mg \\ - $\quad$ po forneuro $1 \mathrm{x} 1$ \\ - ASA $1 \times 1$}

\section{Hasil Pemeriksaan Penunjang Laboratorium}

\section{Desember 2016}

\section{Kimia darah}

Gula darah sesaat : $122 \mathrm{mg} / \mathrm{dl}$

Ureum

$$
\text { (10-50) }
$$

$\begin{array}{lcc}\text { creatinin } & : 0.99 \mathrm{n} \mathrm{mg} / \mathrm{dl} & (0.7-1.5) \\ \text { SGOT } & : 79 \mathrm{U} / \mathrm{l} & (12-41) \\ \text { SGPT } & : 57 & \end{array}$

$$
\text { (10-41) }
$$

albumin $\quad: 4.50 \mathrm{~g} / \mathrm{dl}$

\section{Analisa Elektrolit}

$\begin{aligned} & \text { natrium } \\ & \text { 145) } \\ & \text { kaliun }\end{aligned}$
chlorida $\quad: 117 \mathrm{mmol} / \mathrm{l} \quad(136-$

\section{Des 2016}

\section{Kimia Darah}

kolesterol total : $155 \mathrm{mg} / \mathrm{dl}$

$$
\text { (130-220) }
$$

kolesterol HDL $\quad: 31 \mathrm{mg} / \mathrm{dl} \quad(>50)$ kolesterol LDL $\quad: 119 \mathrm{mg} / \mathrm{dl} \quad(<150)$

$$
\begin{aligned}
& \text { trigliserida } \\
& \text { (34-143) } \\
& \text { asam urat } \\
& \text { CRP } \quad(<0.3) \\
& \text { : } 123 \mathrm{mg} / \mathrm{dl} \\
& \text { : } 6 \mathrm{mg} / \mathrm{dl} \\
& \text { : } 3.96 \mathrm{mg} / \mathrm{dl}
\end{aligned}
$$

Seroimunologi

$\begin{array}{lll}\text { ASO/ ASTO } & :- & (<200 \mathrm{IU} / \mathrm{ml}) \\ \text { VDRL } & :- & \\ \text { TPHA } & :- & \end{array}$

TB ICT : -

\section{Desember 2016}

CT scan kepala tanpa dan dengan kontras, irisan axial, brain window, sejajar OM line, tebal irisan $10 \mathrm{~mm}$ :

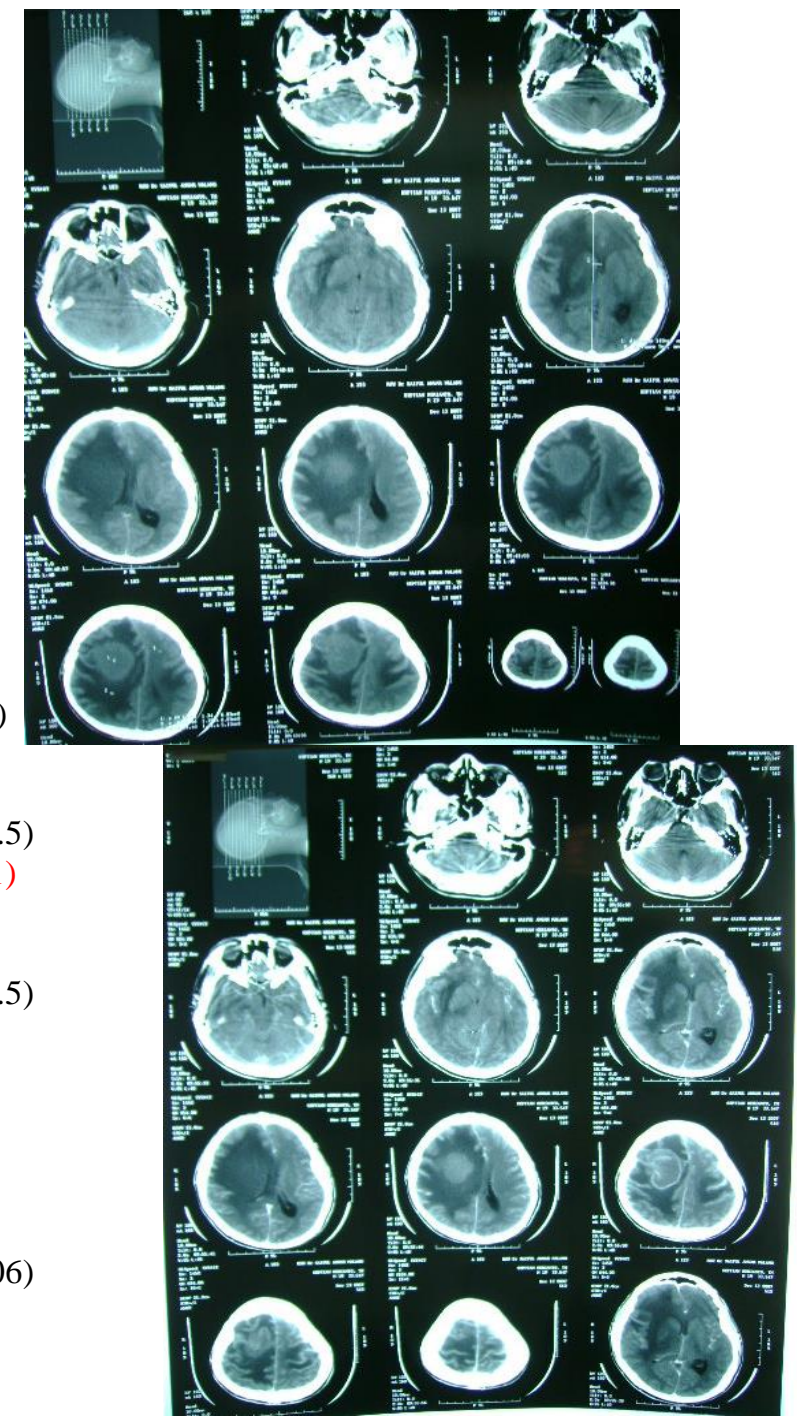

- tampak lesi hiperdens yang menyangat pada tepinya (ring like) pada lobus frontoparietal dextra, 
dengan edema perifokal luas berbentuk finger like, menyebabkan obliterasi ventrikel lateralis dextra, serta mendorong ventrikel 3 dan garis midline ke kiri sejauh $9 \mathrm{~mm}$. Ventrikel lateralis cornu anterior sinistra menyempit, cornu posterior dilatasi

- tampak pula lesi hiperdens dengan edema perifokal pada lobus parietalis sinistra

- tampak penyangatan meningen setelah pemberian kontras

- $\quad$ ventrikel 4 normal

- $\quad$ sisterna quadrigeminal dan ambient menyempit

- infratentorial : pons, cerebellum dan kedua CPA normal

- $\quad$ sella dan parasella normal

- mastoid dextra/ sinistra, sinus frontalis, ethmoid dan sphenoid normal

- orbita dextra/ sinistra normal

Kesan CT Scan:

tumor supratentorial pada lobus frontoparietal dextra suspect high grade astrocytoma yang menyebabkan edema perifokal dan herniasi sub falcine ke sinistra dengan Leptomeningeal carcinomatosis DD: Leptomeningeal carcinomatosis

\section{PEMBAHASAN}

Diagnosa etiologis awal pada pasien ini adalah susp CVA trombosis, karena pelo terjadi saat aktivitas pasien istirahat dan onsetnya mendadak, kemudian ditunjang riwayat kelemahan badan sebelah kiri sebelumnya.

Diagnosa topis pasien ini adalah cortex karena kesadaran pasien saat serangan masih tetap baik, terjadi disartria dan kelemahan anggota badan. Hal ini ditunjang oleh peningkatan tonus sisi kiri, peningkatan refleks fisiologis sisi kiri dan refleks patologis sisi kiri yang berarti kelainan adalah UMN.

Dari pemeriksaan CT ternyata menunjukkan lesi hiperdens yang menyangat pada tepinya (ring like) pada lobus frontoparietal dextra, dengan edema perifokal luas berbentuk finger like, menyebabkan obliterasi ventrikel lateralis dextra, serta mendorong ventrikel 3 dan garis midline ke kiri sejauh $9 \mathrm{~mm}$. Tampak juga lesi hiperdens pada lobus parietalis sinistra dengan edema perifokal.
Ventrikel lateralis cornu anterior sinistra menyempit, cornu posterior dilatasi dan tampak penyangatan meningen setelah pemberian kontras. Kesimpulan dari pemeriksaan CT adalah tumor supratentorial pada lobus frontoparietal dextra suspect astrocytoma high grade yang menyebabkan edema perifokal dan herniasi sub falcine ke sinistra denga Leptomeningeal carcinomatosis DD: Leptomeningeal carcinomatosis. Hal ini didukung dari anmnesa kelemahan badan sebelah kiri, nyeri kepala sisi kanan dan kejang yang muncul sejak lama sehingga merupakan kelainan yang sifatnya kronis dan kelainan anatomi berada pada cortex cerebri dextra. Sakit kepala merupakan manifestasi peningkatan tekanan intracranial yang terjadi karena efek massa. Tetapi pada pasien ini tidak didaptkan manifestasi lain seperti muntah atau papiledema.

Kemungkinan ketidakcocokan diagnosa awal dengan hasil CT, karena tumor bisa memberikan manifestasi klinis yang sangat luas dan kadang menyerupai suatu CVA karena efek penekanan massa terhadap vascular atau gangguan vascular akibat infiltrasi massa/ sel metastase.

\section{KESIMPULAN}

- Astrocytoma adalah tumor yang berasal dari sel astrocyt (salah satu jenis sel glia, fibrilar, protoplasmic atau gemistocytic astrocyt yang tumbuh pelan tetapi invasif

- Tumor otak menyebabkan gangguan neurologi progresif. Hal ini menekankan pentingnya ananmesa

- Astrocytoma supratentorial menunjukkan lesi hipodens dengan derajat penyangatan kontras berbedabeda

- Terapi astrocytoma tergantung pada lokasi dan derajat tumor, pasien dengan hidrocephalus obstruktif memerlukan penempatan ventriculoperitoneal shunt

- Komplikasi yang sering timbul adalah hidrocephalus obstruktif

\section{DAFTAR PUSTAKA}

1. Peter Duus. Diagnosis Topis Neurologi Anatomi, Fisiologi, Tanda, Gejala. EGC. Jakarta. 1996.

2. Sylvia Price. Patofisiologi Konsep Klinis Proses-proses Penyakit Buku 2. Jakarta: Penerbit Buku Kedokteran EGC;1992 
3. Wita Suwono. Diagnosis Topik Neurologi Anatomi, Fisiologi, tanda dan Gejala. Jakarta: Penerbit Buku Kedokteran EGC 1996

4. Sebastian lange. Cerebral and Spinal Computerized Tomography. Schering. Germany. 1989

5. Anonymous. Astrocytoma. Adapted from: www.emedicine.com, 2016.

6. Anonymous. Glioblastoma. Adapted from: www.emedicine.com, 2016.

7. Anonymous. Leptomeningeal carcinomatosis. Adapted from: www.emedicine.com, 2016. 